\title{
Misturas de Herbicidas no manejo de Plantas Daninhas na Cultura do FeiJÃo ${ }^{1}$
}

\author{
Herbicide Mixtures in Weed Management in Bean Culture \\ MACHADO, A.F.L. ${ }^{2}$, CAMARGO, A.P.M. ${ }^{3}$, FERREIRA, L.R. ${ }^{4}$, SEDIYAMA, T. ${ }^{4}$, FERREIRA, F.A. ${ }^{4}$ e
VIANA, R.G. ${ }^{2}$
}

\begin{abstract}
RESUMO - Avaliou-se a eficácia da combinação dos herbicidas fomesafen, fluazifop-p-butil e bentazon no manejo integrado de plantas daninhas do feijoeiro (plantio direto e convencional), cultivados em áreas anteriormente com milho para grão e silagem. Foi avaliado também o resíduo do fomesafen no solo aos 125 dias após a aplicação (DAA). No plantio convencional, Cyperus rotundus foi a espécie dominante, enquanto no plantio direto a infestação dessa espécie foi muito baixa. Nenhuma das combinações de herbicidas foi eficiente no controle de C. rotundus. Com exceção de fluazifop-p-butil + bentazon $\left(125+480 \mathrm{~g}^{h^{-1}}\right)^{-}$, todas as combinações foram eficientes no controle das espécies daninhas dicotiledôneas. Não houve efeito dos tratamentos de herbicidas na produtividade do feijoeiro. O fomesafen, aplicado no plantio direto, causou toxicidade no feijão a partir da dose de $100 \mathrm{~g}^{\text {ha-1, }}{ }^{-1}$ sobretudo no milho para silagem. No plantio convencional, sintomas mais leves somente foram observados na dose de $200 \mathrm{~g} \mathrm{ha}^{-1}$. Houve resíduo de fomesafen no solo apenas na área de plantio direto onde não havia palhada sobre a superfície do solo, ou seja, na área anteriormente cultivada com milho para silagem. É possivel reduzir doses do fomesafen quando misturado ao bentazon sem afetar a produtividade do feijoeiro. Em áreas de feijão cultivado após colheita do milho para silagem é importante o uso de doses pequenas do fomesafen, para evitar toxicidade a culturas sensiveis subseqüentes.
\end{abstract}

Palavras-chave: plantio direto, manejo do solo, plantas daninhas, Phaseolus vulgaris.

\begin{abstract}
This work aimed to evaluate the efficacy of combining the herbicides fomesafen, fluazifop-p-butyl and bentazon for integrated weed management in bean culture (no-tillage and conventional tillage), in areas previously cultivated with maize for grain and silage. Fomesafen residue in the soil was also evaluated at 125 days after application (DAA). In the conventional tillage, Cyperus rotundus was the dominant species, while under no-tillage, infestation of this species was very low. None of the herbicide combinations was efficient in controlling $\mathbf{C}$. rotundus. Except for fluazifop-p-butyl + bentazon $\left(125+480 \mathrm{~g} \mathrm{ha}^{-1}\right)$, all the combinations were efficient in controlling the dicotyledonous weed species. The herbicide treatments had no effect on bean productivity. Fomesafen, applied under no-tillage, caused toxicity to the bean culture after the dose of $100 \mathrm{~g} \mathrm{ha}^{-1}$, especially to silage corn. Under the conventional tillage, milder symptoms were only observed at the dose of $200 \mathrm{~g} \mathrm{ha}^{-1}$. Fomesafen residue was found in the soil only in the no-tillage area without straw on the soil surface, in the area previously cultivated with maize for silage. Fomesafen doses can be reduced when mixed with bentazon without affecting bean productivity. In areas where bean was cultivated after maize harvest for silage, it is important to use small doses of fomesafen to prevent subsequent toxicity of sensitive cultures.
\end{abstract}

Keywords: no-tillage, soil management, weeds, Phaseolus vulgaris.

Recebido para publicação em 12.4.2005 e na forma revisada em 24.2.2006.

2 Mestrando do Departamento de Fitotecnia da Universidade Federal de Viçosa - UFV, 36570-000 Viçosa-MG, <aroldomachado@yahoo.com.br>; ${ }^{3}$ Eng.-Agrônomia, mestre em Fitotecnia; ${ }^{3}$ Professor do Departamento de Fitotecnia da UFV.

Planta Daninha, Viçosa-MG, v. 24, n. 1, p. 107-114, 2006 


\section{INTRODUÇÃO}

Na cultura do feijão, a interferência das plantas daninhas pode causar redução de 15 a $80 \%$ no rendimento (Kozlowski et al., 2002). $\mathrm{O}$ uso correto de herbicidas possibilita grande eficiência de controle das plantas daninhas, maior praticidade e maior rendimento de grãos. Para controle de espécies dicotiledôneas destacam-se o fomesafen e o bentazon e, para gramíneas, o fluazifop-p-butil. A mistura pronta, fluazifop-p-butil + fomesafen, apresenta amplo espectro de controle, controlando dicotiledôneas e gramíneas (Ferreira et al., 1998).

Em muitas situações, as doses dos herbicidas são superestimadas, proporcionando período de controle superior ao necessário (Timossi \& Durigan, 2002). A mistura de herbicidas no tanque de pulverização - prática comum entre os agricultores - oferece algumas vantagens em relação ao uso de um único produto, como aumento do número de espécies controladas, melhor controle de determinadas espécies, redução do custo de pulverização e possibilidade de redução da dose recomendada. Esta última vantagem tem como conseqüência a diminuição de resíduos no solo e da toxicidade à cultura.

O tipo de preparo do solo influencia tanto quantitativa quanto qualitativamente as populações de plantas daninhas. Em comparação com o plantio convencional, no direto ocorre diminuição da população de diversas espécies, como, por exemplo, Brachiaria plantaginea, Amaranthus viridis (Pereira et al., 2000) e Cyperus rotundus (Machado et al., 2005). $\mathrm{O}$ não-revolvimento do solo, associado à presença de resíduos vegetais na sua superfície, é o principal fator responsável por esse fato (Mulugueta \& Stoltenberg, 1997). O tipo e a quantidade de resíduos vegetais presentes na superfície do solo influenciam a germinação de sementes e o estabelecimento das espécies (Yenish et al., 1996).

A degradação e a movimentação dos herbicidas no solo podem ser influenciadas pela textura, $\mathrm{pH}$, teor de matéria orgânica, umidade e temperatura do solo; pelas características físicas e químicas dos herbicidas; e pelas doses utilizadas (Ferri \& Vidal, 2002). O manejo do solo pode alterar a persistência dos herbicidas, o que influencia a eficiência de controle, o potencial de injúria às culturas em sucessão e o risco de contaminação ambiental (Ferri \& Vidal, 2002). No plantio direto, os restos culturais que permanecem na superfície podem influenciar as características físicas, químicas e microbiológicas do solo, alterando a persistência dos herbicidas no ambiente. $\mathrm{O}$ não-revolvimento do solo e o aumento da cobertura morta na superfície diminuem a amplitude térmica, conservam melhor a água do solo e incrementam o teor de matéria orgânica na sua superfície. Conseqüentemente, ocorre aumento na atividade microbiológica e na biotransformação das moléculas dos herbicidas, o que acelera a sua taxa de degradação no solo (Shaw \& Murphy, 1997).

No Brasil, as condições climáticas favorecem a dissipação dos herbicidas e, por outro lado, propiciam o cultivo intensivo da terra, reduzindo o intervalo de tempo entre o plantio das culturas e as aplicações dos herbicidas. Alguns trabalhos comprovam o efeito residual do fomesafen, aplicado nas culturas da soja e do feijão, causando toxicidade às culturas do milho e sorgo plantados em sucessão (Rodrigues \& Almeida, 1998; Cobucci, 1996).

O objetivo desta pesquisa foi avaliar as combinações de fomesafen com fluazifop-pbutil e bentazon no manejo integrado de plantas daninhas no feijoeiro e também o resíduo no solo do fomesafen aos 125 DAA, em áreas de plantios direto e convencional.

\section{MATERIAL E MÉTODOS}

Foram conduzidos quatro experimentos em quatro diferentes ambientes agrícolas: plantio convencional do milho para silagem (PCMS); plantio convencional do milho para grão (PCMG); plantio direto do milho para silagem (PDMS); e plantio direto do milho para grão (PDMG). Os experimentos foram realizados simultaneamente em áreas pertencentes ao Departamento de Fitotecnia da Universidade Federal de Viçosa - UFV, num solo Podzólico Vermelho-Amarelo Câmbico, fase terraço.

Em 1998 essa área foi dividida em duas partes iguais: uma cultivada no sistema plantio direto e a outra no convencional. Desde então, no plantio de primavera/verão, cultiva-se o 
milho em toda a área. Em ambos os sistemas, parte do milho é colhida para silagem (MS) e parte para a produção de grãos (MG), havendo, assim, quatro ambientes agrícolas: PCMS, PCMG, PDMS e PDMG. Na área destinada à produção de milho para silagem, toda a palhada foi retirada, enquanto na produção de grão esta permaneceu no campo, como cobertura morta. Cada ambiente agrícola descrito constituiu um experimento com a cultura do feijão, no período de abril a agosto de 2002.

Nas áreas de plantio direto, a dessecação das plantas daninhas foi realizada 10 dias antes do plantio do feijão com a mistura de glyphosate + 2,4-D $\left(1.440+670 \mathrm{~g} \mathrm{ha}^{-1}\right)$. Dois dias antes do plantio do feijão nas áreas de plantio convencional, foram realizadas uma aração e duas gradagens. O plantio do feijão, variedade Meia Noite, foi feito em 23 de abril. Foram empregados na adubação $250 \mathrm{~kg} \mathrm{ha}^{-1}$ da mistura de $\mathrm{N}, \mathrm{P}_{2} \mathrm{O}_{5}$ e $\mathrm{K}_{2} \mathrm{O}$, na proporção de 8:28:16.

Os tratamentos (modo de controle) estão apresentados na Tabela 1. Foi usado o delineamento experimental de blocos ao acaso, com quatro repetições. As parcelas foram constituídas por cinco fileiras de feijão de $12 \mathrm{~m}$ cada, espaçadas de $0,45 \mathrm{~m}$, ou seja, a área total foi de $27,0 \mathrm{~m}^{2}$.

A aplicação dos herbicidas foi realizada 24 dias após o plantio do feijão, quando as espécies daninhas dicotiledôneas estavam com duas a quatro folhas verdadeiras e o feijão, com o terceiro trifólio formado. A capina com enxada foi feita aos 24 e 39 dias após o plantio, nas parcelas da testemunha com capina.

Para o levantamento das espécies de plantas daninhas, foram realizadas amostragens nos quatro experimentos, com um quadrado de metal com 0,3 m de lado. Na primeira amostragem, um dia antes da aplicação dos herbicidas, foram feitos dois lançamentos do quadrado em cada tratamento de cada ambiente agrícola (PCMG, PCMS, PDMG e PDMS). Avaliaram-se o número e a massa por espécie daninha seca. Na segunda, aos 28 dias após aplicação dos herbicidas, avaliou-se a massa por espécie seca, também com dois lançamentos do quadrado por parcela. Os dados da segunda avaliação foram transformados em porcentagem de massa seca em relação à média das testemunhas sem capina. Após a colheita, avaliaram-se as produtividades do feijoeiro.

Para determinação da produtividade foram colhidas e contadas todas as plantas presentes em $5 \mathrm{~m}$ de comprimento de duas das três fileiras centrais de cada parcela. Após debulha, os grãos com teor de água de 13\% (BU) foram pesados em balança com precisão de 0,01 g.

Para avaliar o resíduo de fomesafen no solo, foram coletadas amostras na profundidade de 0 a $10 \mathrm{~cm}$, aos 125 dias após aplicação, em quatro pontos ao acaso, em cada parcela dos experimentos. As amostras simples foram misturadas e homogeneizadas. Em seguida, a amostra composta foi peneirada e colocada em cinco vasos, com capacidade para $300 \mathrm{~cm}^{3}$, revestidos internamente com saco de polietileno. Em cada vaso foram colocadas cinco

Tabela 1 - Modos de controle avaliados para manejo das plantas daninhas na cultura do feijão, nos quatro ambientes agrícolas

\begin{tabular}{|c|c|c|}
\hline \multirow{2}{*}{ Modo de Controle } & Produto comercial & Ingrediente ativo \\
\hline & $\left(\mathrm{L} \mathrm{ha}^{-1}\right)$ & $\left(\mathrm{g} \mathrm{ha}^{-1}\right)$ \\
\hline Testemunha com capina & - & - \\
\hline Testemunha sem capina & - & - \\
\hline (fluazifop-p-butil + bentazon $)^{\frac{1 /}{}}$ & $1,0+1,0$ & $125+480$ \\
\hline (fluazifop-p-butil + fomesafen) ${ }^{2 /}$ & 0,8 & $(160+200)$ \\
\hline (fluazifop-p-butil + fomesafen) $)^{2 !}$ & 0,4 & $(80+100)$ \\
\hline [(fluazifop-p-butil + fomesafen) + bentazon] $]^{3 /}$ & $0,2+0,8$ & $(40+50)+384$ \\
\hline [(fluazifop-p-butil + fomesafen) + bentazon] $]^{3 /}$ & $0,4+0,6$ & $(80+100)+288$ \\
\hline$\left[(\text { fluazifop-p-butil + fomesafen) + bentazon }]^{\frac{3}{1}}\right.$ & $0,5+0,5$ & $(100+125)+240$ \\
\hline
\end{tabular}

${ }^{1 /}$ Mistura no tanque de Fusilade e Basagran; $\stackrel{2}{2}$ mistura pronta denominada Robust; $\stackrel{3}{~}$ mistura no tanque de Robust e Basagran. 
sementes pré-germinadas de sorgo AG 1501, a $0,5 \mathrm{~cm}$ de profundidade. A irrigação foi diária e o solo foi mantido próximo à capacidade de campo. A adubação foi feita com fertilizante Ouro Verde (0,2 g por vaso), aos sete dias após a emergência.

Os sintomas de intoxicação do sorgo, causados pelo fomesafen, foram avaliados aos 19 dias após a semeadura (DAS), atribuindose notas conforme a escala adaptada do EWRC (Frans, 1972). Aos 21 DAS, as plantas de sorgo foram colhidas e secadas em estufa de ventilação forçada, a $70{ }^{\circ} \mathrm{C}$, por 72 horas, determinando-se a seguir a massa da parte aérea seca.

Os dados referentes às espécies de plantas daninhas e à toxidez dos herbicidas às plantas de sorgo foram analisados utilizando-se estatística descritiva. Os dados de produtividade do feijoeiro e de massa da parte aérea seca do sorgo foram submetidos à análise de variância individual e conjunta dos quatro experimentos. Independentemente da significância da interação, foi efetuado o seu desdobramento. $\mathrm{Na}$ análise de variância, utilizou-se o teste $\mathrm{F}$ a $5 \%$ de probabilidade, e, sendo o teste $\mathrm{F}$ significativo, as médias foram comparadas pelo teste de Tukey a 5\% de significância.

\section{RESULTADOS E DISCUSSÃO}

Nos quatro ambientes agrícolas ocorreu maior infestação de espécies dicotiledôneas (Tabela 2). O plantio convencional favoreceu a ocorrência de mastruço (Coronopus didymus), tiririca (Cyperus rotundus) e trevo (Oxalis latifolia), com predomínio de $C$. rotundus, cuja massa seca atingiu 113,90 e $66,26 \mathrm{~g} \mathrm{~m}^{-2}$ nos cultivos de milho para grão e silagem, respectivamente (Tabela 2). No plantio direto, as espécies dominantes foram C. didymus e $O$. latifolia. A infestação de $C$. rotundus foi muito baixa (Tabela 2). A baixa ocorrência de C. rotundus na área de plantio direto se deve ao manejo de não-revolvimento do solo iniciado em 1998 (Machado et al., 2005). Segundo

Tabela 2 - Número médio de plantas daninhas por espécie $\left(\mathrm{N} \mathrm{m}^{-2}\right)$ e massa seca $\left(\mathrm{g} \mathrm{m}^{-2}\right)$, avaliado um dia antes da aplicação dos herbicidas em pós-emergência na cultura do feijão, nos quatro ambientes agrícolas

\begin{tabular}{|c|c|c|c|c|c|c|c|c|}
\hline \multirow{3}{*}{ Espécie } & \multicolumn{4}{|c|}{ Plantio convencional } & \multicolumn{4}{|c|}{ Plantio direto } \\
\hline & \multicolumn{2}{|c|}{ Grão } & \multicolumn{2}{|c|}{ Silagem } & \multicolumn{2}{|c|}{ Grão } & \multicolumn{2}{|c|}{ Silagem } \\
\hline & $\left(\mathrm{N} \mathrm{m}^{-2}\right)$ & $\left(\mathrm{g} \mathrm{m}^{-2}\right)$ & $\left(\mathrm{N} \mathrm{m}^{-2}\right)$ & $\left(\mathrm{g} \mathrm{m}^{-2}\right)$ & $\left(\mathrm{N} \mathrm{m}^{-2}\right)$ & $\left(\mathrm{g} \mathrm{m}^{-2}\right)$ & $\left(\mathrm{Nm}^{-2}\right)$ & $\left(\mathrm{g} \mathrm{m}^{-2}\right)$ \\
\hline Amaranthus sp. & 28,17 & 0,36 & 33,73 & 0,11 & 16,27 & 0,27 & 1,59 & 0,00 \\
\hline Bidens pilosa & 0,40 & 0,01 & - & - & - & - & 0,40 & 0,00 \\
\hline Brachiaria plantaginea & 0,40 & 0,01 & - & - & - & - & - & - \\
\hline Coronopus didymus & $1.907,94$ & 6,08 & $2.109,92$ & 14,63 & 967,06 & 4,03 & $1.668,25$ & 7,56 \\
\hline Cyperus rotundus & $1.139,68$ & 113,90 & $1.264,29$ & 66,26 & 2,78 & 0,62 & 0,79 & 0,12 \\
\hline Digitaria horizontalis & - & - & - & - & - & - & 5,95 & 0,01 \\
\hline Emilia sonchifolia & 0,40 & 0,00 & - & (n) & - & - & 0,79 & 0,01 \\
\hline Euphorbia heterophylla & - & - & 0,79 & 0,02 & 0,79 & 0,10 & 0,40 & 0,03 \\
\hline Galinsoga parviflora & 34,92 & 0,23 & 17,86 & 0,10 & 11,51 & 0,09 & 40,87 & 0,31 \\
\hline Ipomoea grandifolia & 0,79 & 0,02 & 3,57 & 0,14 & - & - & - & - \\
\hline Lepidium virginicum & - & - & - & - & - & - & 51,98 & 0,12 \\
\hline Mucuna aterrima & - & - & 0,79 & 0,50 & - & - & 0,79 & 0,28 \\
\hline Oxalis latifólia & 636,11 & 9,95 & 533,33 & 7,98 & 552,38 & 10,48 & 98,81 & 1,30 \\
\hline Sinapsis arvensis & 119,05 & 3,42 & 5,95 & 0,10 & - & - & - & - \\
\hline Solanum americanum & 2,38 & 0,02 & 4,37 & 0,03 & - & - & - & - \\
\hline Sonchus oleraceus & 1,98 & 0,01 & 1,59 & 0,00 & 5,56 & 0,06 & 2,78 & 0,23 \\
\hline Stachys arvensis & 17,46 & 0,11 & 9,92 & 0,08 & 1,98 & 0,03 & - & - \\
\hline Total de plantas daninhas & $3.889,68$ & $1.34,11$ & $3.986,11$ & 89,95 & $1.558,33$ & 15,67 & $1.873,41$ & 9,98 \\
\hline Ciperáceas & $1.139,68$ & $1.13,90$ & $1.264,29$ & 66,26 & 2,78 & 0,62 & 0,79 & 0,12 \\
\hline Gramíneas & 0,40 & 0,01 & - & - & - & - & 5,95 & 0,01 \\
\hline Dicotiledôneas & 2749,60 & 20,20 & 2721,83 & 23,72 & 1555,56 & 15,06 & 1866,67 & 9,86 \\
\hline
\end{tabular}


Ferreira et al. (2000), o preparo do solo no sistema de plantio convencional favorece a propagação e o estabelecimento de $C$. rotundus devido à fragmentação dos tubérculos e quebra de dormência, através da eliminação da dominância apical destes. No plantio direto, além do não-revolvimento do solo, o glyphosate e o 2,4-D, utilizados como dessecantes, eliminaram temporariamente a parte aérea dessa ciperácea e contribuíram para a redução do número de tubérculos formados por planta (Machado et al., 2005; Jakelaitis et al., 2003).

Nenhuma combinação de herbicidas foi eficiente para controle de $C$. rotundus no plantio convencional (Tabela 3). Neste plantio, onde o feijão foi cultivado na área em que foi colhido milho para grão, todas as combinações de herbicidas foram eficientes no controle de C. didymus (Tabela 3). Nos demais ambientes agrícolas, com exceção da mistura fluazifop- p-butil + bentazon $\left(125+480 \mathrm{~g} \mathrm{ha}^{-1}\right)$, as outras também foram eficientes no controle dessa espécie (superior a 75\%).

A mistura fluazifop-p-butil + bentazon $\left(125+480 \mathrm{~g} \mathrm{ha}^{-1}\right)$ não foi eficiente no controle das plantas daninhas dicotiledôneas (Tabela 4). As espécies C. didymus, G. parviflora, Amaranthus sp., E. heterophylla, L. virginicum e S. americanum não foram controladas por essa mistura. Cobucci (1996) também não obteve controle eficiente de Amaranthus hybridus e E. heterophylla com o bentazon.

A eficiência de controle das plantas daninhas, evidenciada pela menor produção de massa seca da parte aérea, foi satisfatória em todas as combinações de herbicidas no plantio direto, o que não ocorreu no convencional, uma vez que a infestação de $C$. rotundus foi muito alta (Tabela 4).

Tabela 3 - Porcentagem de massa da parte aérea seca de Cyperus rotundus (CYPRO) e Coronopus didymus (COPDI) em relação à massa $\left(\mathrm{g} \mathrm{m}^{-2}\right)$ da testemunha, aos 28 dias após aplicação dos herbicidas na cultura do feijão

\begin{tabular}{|c|c|c|c|c|c|c|c|c|c|}
\hline \multirow{3}{*}{ Modo de controle } & \multirow{3}{*}{$\begin{array}{c}\text { Dose } \\
\left(\mathrm{g} \mathrm{ha}^{-1}\right)\end{array}$} & \multicolumn{4}{|c|}{ Plantio convencional } & \multicolumn{4}{|c|}{ Plantio direto } \\
\hline & & \multicolumn{2}{|c|}{ Grão } & \multicolumn{2}{|c|}{ Silagem } & \multicolumn{2}{|c|}{ Grão } & \multicolumn{2}{|c|}{ Silagem } \\
\hline & & CYPRO $\%$ & COPDI $\%$ & CYPRO \% & COPDI\% & CYPRO \% & COPDI $\%$ & CYPRO \% & COPDI\% \\
\hline$\left(\text { Fluz }^{1 /}+\text { Bent }^{2 / /}\right)^{4 /}$ & $125+480$ & 75,97 & 2,59 & 42,68 & 81,54 & 0,00 & 56,80 & 0,00 & 33,26 \\
\hline$\left.\left(\text { Fluz }^{1 /}+\text { Fomf }^{3}\right)^{\prime /}\right)^{\frac{1}{\prime \prime}}$ & $160+200$ & 130,14 & 0,24 & 74,08 & 7,71 & 5,26 & 2,70 & 0,00 & 0,45 \\
\hline$\left(\text { Fluz }^{1 /}+\text { Fomf }^{3 /}\right)^{5 /}$ & $80+100$ & 140,95 & 3,30 & 93,50 & 4,26 & 0,00 & 36,40 & 0,00 & 6,22 \\
\hline$\left(\left(\text { Fluz }^{1 /}+\text { Fomf }^{3 /}\right)+\text { Bent }^{2}\right)^{6 /}$ & $(40+50)+384$ & 68,83 & 2,36 & 64,49 & 24,75 & 5,26 & 15,77 & 0,00 & 7,05 \\
\hline$\left(\left(\text { Fluz }^{1 /}+\text { Fomf }^{3 /}\right)+\text { Bent }^{2}\right)^{6 /}$ & $(80+100)+288$ & 100,60 & 0,71 & 54,76 & 0,53 & 0,00 & 36,04 & 0,00 & 5,04 \\
\hline$\left(\left(\text { Fluz }^{1 /}+\text { Fomf }^{3 / 3}\right)+\text { Bent }^{2^{\prime}}\right)^{6 / 1}$ & $(100+125)+240$ & 97,89 & 1,89 & 56,27 & 7,30 & 10,53 & 0,00 & 0,00 & 1,18 \\
\hline \multirow{2}{*}{ Testemunha sem capina } & & \multicolumn{8}{|c|}{ Massa seca $\left(\mathrm{g} \mathrm{m}^{-2}\right)$} \\
\hline & & 180,56 & 11,78 & 140,50 & 13,69 & 0,53 & 12,33 & 0,00 & 49,61 \\
\hline
\end{tabular}

${ }^{1 /}$ fluazifop-p-butil; ${ }^{2 /}$ bentazon; ${ }^{3 /}$ fomesafen; ${ }^{4 /}$ mistura no tanque de Fusilade e Basagran; ${ }^{5 /}$ mistura pronta denominada Robust; ${ }^{6 /}$ mistura no tanque de Robust e Basagran.

Tabela 4 - Porcentagem da massa das plantas daninhas secas, dicotiledôneas (DICT) e total de plantas daninhas (TOTAL), em relação à testemunha, avaliadas aos 28 dias após aplicação dos herbicidas na cultura do feijão

\begin{tabular}{|c|c|c|c|c|c|c|c|c|c|}
\hline \multirow{3}{*}{ Modo de controle } & \multirow{3}{*}{$\begin{array}{l}\text { Dose } \\
\left(\mathrm{g} \mathrm{ha}^{-1}\right)\end{array}$} & \multicolumn{4}{|c|}{ Plantio convencional } & \multicolumn{4}{|c|}{ Plantio direto } \\
\hline & & \multicolumn{2}{|c|}{ Grão } & \multicolumn{2}{|c|}{ Silagem } & \multicolumn{2}{|c|}{ Grão } & \multicolumn{2}{|c|}{ Silagem } \\
\hline & & DICT\% & TOTAL\% & DICT\% & TOTAL\% & DICT\% & TOTAL\% & DICT\% & TOTAL\% \\
\hline$\left(\text { Fluz }^{1 /}+\text { Bent }^{2 /}\right)^{4 /}$ & $125+480$ & 28,78 & 62,01 & 95,20 & 50,59 & 115,56 & 35,61 & 36,41 & 36,14 \\
\hline$\left(\text { Fluz }^{1 /}+\text { Fomf }^{3}\right)^{-1}$ & $160+200$ & 11,10 & 97,04 & 16,29 & 65,38 & 20,33 & 6,28 & 7,17 & 7,15 \\
\hline$\left(\text { Fluz }^{1 /}+\text { Fomf }^{3}\right)^{-1}$ & $80+100$ & 6,63 & 104,90 & 20,65 & 82,53 & 22,28 & 6,87 & 11,37 & 11,28 \\
\hline$\left(\left(\text { Fluz }^{1}+\text { Fomf }^{3}\right)+\text { Bent }^{2}\right)^{6 /}$ & $(40+50)+384$ & 8,83 & 52,31 & 28,91 & 59,14 & 25,22 & 7,79 & 10,38 & 10,30 \\
\hline$\left(\left(\text { Fluz }^{1 /}+\text { Fomf }^{3}\right)+\text { Bent }^{2}\right)^{\frac{6}{6}}$ & $(80+100)+288$ & 5,96 & 75,05 & 20,98 & 49,68 & 40,78 & 12,57 & 7,29 & 7,24 \\
\hline$\left(\left(\mathrm{Fluz}^{-1}+\text { Fomf }^{-3}\right)+\text { Bent }^{t^{\prime}}\right)^{6 /}$ & $(100+125)+240$ & 8,26 & 73,53 & 27,23 & 51,90 & 29,22 & 9,04 & 5,48 & 5,64 \\
\hline \multirow{2}{*}{ Testemunha sem capina } & & \multicolumn{8}{|c|}{ Massa seca $\left(\mathrm{g} \mathrm{m}^{-2}\right)$} \\
\hline & & 49,42 & 245,94 & 24,89 & 165,39 & 50,00 & 162,25 & 67,44 & 67,94 \\
\hline
\end{tabular}

${ }^{1 /}$ fluazifop-p-butil; ${ }^{2 /}$ bentazon; ${ }^{3 /}$ fomesafen; ${ }^{4 /}$ mistura no tanque de Fusilade e Basagran; ${ }^{5 /}$ mistura pronta denominada Robust; ${ }^{6 /}$ mistura no tanque de Robust e Basagran. 
Nos quatro experimentos, a produtividade do feijoeiro não foi afetada pelas combinações de herbicidas, indicando que as misturas desses herbicidas foram seletivas para a cultura do feijão e que o controle das invasoras foi suficiente para que se alcançasse a produtividade da testemunha capinada.

A produtividade do feijoeiro cultivado em plantio direto na área do milho para silagem foi inferior (Pdd5\%) à obtida na área do milho para grão na maioria dos tratamentos (Tabela 5). A presença da palha na superfície do solo, além de ser um impedimento físico e químico para a germinação e emergência de plantas daninhas, também propicia condições edafoclimáticas mais favoráveis ao desenvolvimento das plantas de feijão, o que potencializa a produtividade da cultura. De acordo com Rodrigues (1985), a cobertura morta inibe, por efeito físico e/ou alelopático, o desenvolvimento de várias espécies daninhas, sendo possível em alguns casos a redução do uso de herbicidas, capinas ou qualquer outro método complementar de controle.

Não se observaram sintomas de intoxicação, segundo a escala adaptada do EWRC (Frans, 1972), provocados pelo fomesafen nas plantas de sorgo cultivadas em solo coletado aos 125 dias após a aplicação dos herbicidas no feijão, quando este foi cultivado após a cultura do milho para grão em plantio convencional. Em área de milho para silagem (ausência de palhada), no entanto, verificou-se leve toxicidade (clorose internerval) do sorgo quando $200 \mathrm{~g} \mathrm{ha}^{-1}$ de fomesafen foram aplicados na cultura do feijão, o que não afetou o crescimento do sorgo (Tabela 6).

Com exceção da dose de $50 \mathrm{~g} \mathrm{ha}^{-1}$, nas áreas onde o feijão foi cultivado em plantio direto após a colheita do milho para silagem, as doses de fomesafen persistiram no solo aos 125 dias da aplicação. Nesses casos, as plantas de sorgo apresentaram clorose internerval, seguida de necrose das folhas (Tabela 6). O fomesafen apresenta baixa mobilidade no solo e, quando o teor de água neste é pequeno, fica adsorvido aos colóides (Cobucci, 1996). À medida que o teor de água do solo aumenta, o fomesafen é liberado gradativamente para a solução do solo. Assim, ele pode ser absorvido pelas raízes do sorgo, que, dependendo da dose aplicada, podem apresentar sintomas de toxidez na parte aérea (Escher, 2002).

Só houve diferença $(p<0,01)$ entre os ambientes agrícolas na produção de massa na parte aérea de sorgo seco (Tabela 7). O resíduo de fomesafen não afetou a produção de biomassa do sorgo cultivado em solo coletado em áreas onde o feijão foi cultivado em plantio convencional após a colheita do milho para grão e silagem. No plantio direto, isso também ocorreu quando o feijão foi plantado após o milho para grão. Entretanto, no plantio direto em área anteriormente cultivada com milho para silagem,

Tabela 5 - Produtividade média $\left(\mathrm{kg} \mathrm{ha}^{-1}\right)$ do feijoeiro em função dos ambientes agrícolas e dos modos de controle das plantas daninhas

\begin{tabular}{|c|c|c|c|c|c|}
\hline \multirow{3}{*}{ Modo de controle } & \multirow{3}{*}{$\begin{array}{c}\text { Dose } \\
\left(\mathrm{g} \mathrm{ha}^{-1}\right)\end{array}$} & \multicolumn{4}{|c|}{ Produtividade $\left(\mathrm{kg} \mathrm{ha}^{-1}\right)$} \\
\hline & & \multicolumn{2}{|c|}{ Plantio convencional } & \multicolumn{2}{|c|}{ Plantio direto } \\
\hline & & Milho grão & Milho silagem* & Milho grão & Milho silagem \\
\hline Testemunha com Capina & - & $2.349,06 \mathrm{ABa}$ & $2.000,87 \mathrm{~B}$ & $2.828,10 \mathrm{Aa}$ & $2.417,37 \mathrm{ABab}$ \\
\hline Testemunha sem capina & - & $7.34,48 \mathrm{Bb}$ & $1.521,60 \mathrm{~A}$ & $1.789,07 \mathrm{Ab}$ & $1.826,54 \mathrm{Ab}$ \\
\hline$\left(\text { Fluz }^{1 /}+\text { Bent }^{2 /}\right)^{4 /}$ & $125+480$ & $2.119,50 \mathrm{Ba}$ & $1.967,67 \mathrm{~B}$ & $2.673,91 \mathrm{Aa}$ & $2.034,95 \mathrm{Bab}$ \\
\hline$\left(\text { Fluz }^{1 /}+\text { Fomf }^{3 /}\right)^{\frac{5}{}}$ & $160+200$ & $2.315,15 \mathrm{Ba}$ & $2.258,57 \mathrm{~B}$ & $2.920,57 \mathrm{Aa}$ & $2.592,96 \mathrm{ABa}$ \\
\hline$\left(\text { Fluz }^{1 /}+\text { Fomf }^{3 /}\right)^{\frac{5}{\prime}}$ & $80+100$ & $1.879,97 \mathrm{Ba}$ & $1.882,95 \mathrm{~B}$ & $2.781,42 \mathrm{Aa}$ & $2.209,82 \mathrm{Bab}$ \\
\hline$\left(\left(\text { Fluz }^{1 /}+\text { Fomf }^{3 /}\right)+\text { Bent }^{2 /}\right)^{6 /}$ & $(40+50)+384$ & $2.355,23 \mathrm{ABa}$ & $2.083,29 \mathrm{~B}$ & $2.828,46 \mathrm{Aa}$ & $2.453,45 \mathrm{ABab}$ \\
\hline$\left(\left(\text { Fluz }^{1 /}+\text { Fomf }^{3 /}\right)+\text { Bent }^{2 /}\right)^{6}$ & $(80+100)+288$ & $2.411,34 \mathrm{BCa}$ & $2.038,81 \mathrm{C}$ & $3.174,01 \mathrm{Aa}$ & $2.725,03 \mathrm{ABa}$ \\
\hline$\left(\left(\mathrm{Fluz}^{1 /}+\mathrm{Fomf}^{3 /}\right)+\mathrm{Bent}^{2 /}\right)^{6 /}$ & $(100+125)+240$ & $2.156,62 \mathrm{Ba}$ & $2.096,78 \mathrm{~B}$ & $3.019,77 \mathrm{Aa}$ & $2.365,57 \mathrm{Bab}$ \\
\hline
\end{tabular}

${ }^{1 /}$ fluazifop-p-butil; ${ }^{\prime}$ bentazon; ${ }^{3 /}$ fomesafen; ${ }^{4 /}$ mistura no tanque de Fusilade e Basagran; ${ }^{5 /}$ mistura pronta denominada Robust; ${ }^{6 /}$ mistura no tanque de Robust e Basagran. Letras minúsculas comparam os oito modos de controle dentro de cada ambiente agrícola, pelo teste de Tukey a 5\% de probabilidade. Letras maiúsculas comparam os quatro ambientes agrícolas dentro de cada modo de controle, pelo teste de Tukey a 5\% de probabilidade. * F não-significativo $(\mathrm{p}<0,05)$. 
Tabela 6 - Porcentagem de toxidez observada na parte aérea das plantas de sorgo, 19 dias após o seu plantio em amostras de solo coletado aos 125 dias da aplicação dos herbicidas em pós-emergência na cultura do feijão

\begin{tabular}{|c|c|c|c|c|c|}
\hline \multirow{3}{*}{ Modo de Controle } & \multirow{3}{*}{$\begin{array}{l}\text { Dose } \\
\left(\mathrm{g} \mathrm{ha}^{-1}\right)\end{array}$} & \multicolumn{4}{|c|}{ Toxicidade $(\%)$} \\
\hline & & \multicolumn{2}{|c|}{ Plantio convencional } & \multicolumn{2}{|c|}{ Plantio direto } \\
\hline & & Milho grão & Milho silagem & Milho grão & Milho silagem \\
\hline Testemunha com capina & - & 0,0 & 0,0 & 0,0 & 0,0 \\
\hline$\left(\text { Fluz }^{1 /}+\text { Fomf }^{2 /}\right)^{4 /}$ & $160+200$ & 8,4 & 21,2 & 35,0 & 74,0 \\
\hline$\left(\text { Fluz }^{1 /}+\text { Fomf }^{\underline{2}}\right)^{4 \prime}$ & $80+100$ & 0,0 & 0,0 & 12,6 & 49,0 \\
\hline$\left(\left(\text { Fluz }^{1 /}+\text { Fomf }^{2 /}\right)+\text { Bent }^{3 /}\right)^{\frac{5}{}}$ & $(40+50)+384$ & 0,0 & 0,0 & 0,0 & 1,0 \\
\hline$\left(\left(\text { Fluz }^{1 /}+\text { Fomf }^{2}\right)+\text { Bent }^{3 /}\right)^{\frac{5}{}}$ & $(80+100)+288$ & 0,0 & 0,6 & 0,2 & 65,0 \\
\hline$\left(\left(\text { Fluz }^{1 /}+\text { Fomf }^{2 /}\right)+\text { Bent }^{3 /}\right)^{\frac{5}{}}$ & $(100+125)+240$ & 0,0 & (3) & 13,0 & ' \\
\hline
\end{tabular}

${ }^{1 /}$ fluazifop-p-butil; ${ }^{2 /}$ fomesafen; ${ }^{3 /}$ bentazon; ${ }^{4 /}$ mistura pronta denominada Robust; ${ }^{5 /}$ mistura no tanque de Robust e Basagran.

Tabela 7 - Massa da parte aérea seca (g por planta) de sorgo, aos 21 dias após o plantio, cultivado em solo coletado na profundidade de $0-10 \mathrm{~cm}$, aos 125 dias após a aplicação dos herbicidas na cultura do feijão

\begin{tabular}{|c|c|c|c|c|c|}
\hline \multirow{4}{*}{ Modo de Controle } & \multirow{4}{*}{$\begin{array}{c}\text { Dose } \\
\left(\mathrm{g} \mathrm{ha}^{-1}\right)\end{array}$} & \multicolumn{4}{|c|}{ (g por planta) } \\
\hline & & \multicolumn{4}{|c|}{ Ambiente agrícola } \\
\hline & & \multicolumn{2}{|c|}{ Plantio convencional } & \multicolumn{2}{|c|}{ Plantio direto } \\
\hline & & Milho grão* & Milho silagem* & Milho grão* & Milho silagem \\
\hline Testemunha com capina & - & $0,091 \mathrm{~B}$ & $0,095 \mathrm{~B}$ & $0,180 \mathrm{~A}$ & $0,159 \mathrm{~A} \mathrm{a}$ \\
\hline$\left(\text { Fluz }^{1 /}+\text { Fomf }^{2^{\prime \prime}}\right)^{4 !}$ & $160+200$ & $0,097 \mathrm{~B}$ & $0,105 \mathrm{~B}$ & $0,172 \mathrm{~A}$ & $0,077 \mathrm{Bc}$ \\
\hline$\left(\text { Fluz }^{1 /}+\text { Fomf }^{2 /}\right)^{4 /}$ & $80+100$ & $0,099 \mathrm{C}$ & $0,079 \mathrm{C}$ & $0,200 \mathrm{~A}$ & $0,138 \mathrm{Bab}$ \\
\hline$\left(\left(\text { Fluz }^{1 /}+\text { Fomf }^{2 /}\right)+\text { Bent }^{3 /}\right)^{5 /}$ & $(40+50)+384$ & $0,085 \mathrm{C}$ & $0,080 \mathrm{C}$ & $0,169 \mathrm{~A}$ & $0,122 \mathrm{Babc}$ \\
\hline$\left(\left(\text { Fluz }^{1 /}+\text { Fomf }^{2 /}\right)+\text { Bent }^{3 /}\right)^{\frac{5}{}}$ & $(80+100)+288$ & $0,092 \mathrm{~B}$ & $0,096 \mathrm{~B}$ & $0,192 \mathrm{~A}$ & $0,107 \mathrm{Bbc}$ \\
\hline$\left(\left(\text { Fluz }^{1 /}+\text { Fomf }^{2 /}\right)+\text { Bent }^{3 /}\right)^{\frac{5}{}}$ & $(100+125)+240$ & $0,090 \mathrm{~B}$ & $0,088 \mathrm{~B}$ & $0,193 \mathrm{~A}$ & $0,101 \mathrm{Bbc}$ \\
\hline
\end{tabular}

1/ fluazifop-p-butil; ${ }^{2 /}$ fomesafen; ${ }^{3 /}$ bentazon; ${ }^{4 /}$ mistura pronta denominada Robust; ${ }^{5 /}$ mistura no tanque de Robust e Basagran. Letras minúsculas comparam os seis tratamentos dentro de cada ambiente agrícola, pelo teste de Tukey a $5 \%$ de probabilidade. Letras maiúsculas comparam os quatro ambientes agrícolas dentro de cada tratamento, pelo teste $\mathrm{F}$ a $5 \%$ de probabilidade. * F não-significativo ( $\mathrm{p}<0,05)$.

em que o solo estava sem cobertura morta, verificou-se menor produção de biomassa pelas plantas de sorgo cultivadas em solo onde o feijão foi pulverizado com fomesafen, especialmente com doses de 125 e $200 \mathrm{~g} \mathrm{ha}^{-1}$.

Todas as combinações de herbicidas foram seletivas à cultura do feijão. É possivel reduzir as doses do fomesafen, quando este é misturado ao bentazon, sem afetar a eficiência de controle das plantas daninhas e a produtividade do feijoeiro nos quatro ambientes agrícolas. Em área de feijão cultivado após colheita de milho para silagem é importante o uso de doses pequenas do fomesafen no feijoal, para evitar toxicidade à cultura sensivel subseqüente.

\section{LITERATURA CITADA}

COBUCCI, T. Avaliação agronômica dos herbicidas fomesafen e bentazon e efeito de seus resíduos no ambiente, no sistema irrigado feijão milho. 1996. 106 p. Dissertação (Mestrado em Fitotecnia) - Universidade Federal de Viçosa, 1996.

ESCHER, V. Eficiência do fomesafen, isolado e em mistura com bentazon na cultura do feijão e seus efeitos residuais na cultura do sorgo, em sucessão. 2002. 50 p. Dissertação (Mestrado em Fitotecnia) - Universidade Federal de Viçosa, 2002.

FERRI, M. V. W.; VIDAL, R. A. Persistência do acetochlor em solo sob semeadura direta e convencional. Planta Daninha, v. 20, n. 1, p. 133-139, 2002. 
FERREIRA, F. A. et al. Manejo de plantas daninhas. In: VIEIRA, C., DE PAULA Jr., T. J.; BORÉM, A. (Ed.). Feijão: aspectos gerais da cultura no Estado de Minas. Viçosa, MG: Universidade Federal de Viçosa, 1998. p. 325-355.

FERREIRA, F. A. et al. Manejo integrado de plantas daninhas em hortaliças. In: MANEJO INTEGRADO DE DOENÇAS, PRAGAS E PLANTAS DANINHAS, 3., 2000, Viçosa, MG. Palestras...Viçosa, MG: 2000. p. 583-608.

FRANS, R. E. Measuring plant response. In: WILKINSON, R. E. (Ed.). Research methods in weed science [S.1.]: South. Weed Sci. Soc., p. 28-41, 1972.

JAKELAITIS, A. et al. Efeitos de sistemas de manejo sobre a população de tiririca. Planta Daninha, v. 21, n. 1, p. 89-96, 2003.

KOZLOWSKI, L. A. et al. Período crítico de interferência das plantas daninhas na cultura do feijoeiro-comum em sistema de semeadura direta. Planta Daninha, v. 20, n. 2, p. 213-220, 2002.

MACHADO, A. F. L. et al. Population dynamics of weeds in no-tillage and conventional crop systems. J. Environ. Sci. Health, v. B40, p. 119-128, 2005.
MULUGUETA, D.; STOLTENBERG, D. E. Increase weed emergence and seed bank depletion by soil disturbance in notillage systems. Weed Sci., v. 45, p. 234-241, 1997.

PEREIRA, E. S. et al. Avaliações qualitativas e quantitativas de plantas daninhas na cultura da soja submetida aos sistemas de plantio direto e convencional. Planta Daninha, v. 18, n. 2, p. 207-216, 2000.

RODRIGUES, B. N. Utilização de herbicidas em plantio direto. In: FANCELLI, A. L. Atualização em plantio direto. Campinas: Fundação Cargil, 1985. p. 51-85.

RODRIGUES, B. N.; ALMEIDA, F. S. Guia de herbicidas. 4. ed. Londrina: Edição dos autores, 1998. 648 p.

SHAW, D. R.; MURPHY, G. P. Field persistence of bioavailable flumetsulam. Weed Sci., v. 45, n. 2, p. 568-572, 1997.

TIMOSSI, P. C.; DURIGAN, J. C. Doses reduzidas de fluazifop-p-butil + fomesafen no controle de plantas daninhas na cultura da soja. Planta Daninha, v. 20, n. 3, p. 439-447, 2002.

YENISH, J. P.; WORSHAM, A. D.; YORK, A. C. Cover crops for herbicide replacement in no-tillage corn (Zea mays). Weed Technol., v. 10, p. 815-821, 1996. 